\title{
Biliteracy and Multilingualism: Implications of English Language Classroom Interactions in Nigeria
}

\author{
Dr. John S. Ereke, Ph.D \\ Department of Arts and Social Science Education \\ Faculty of Education \\ Ebonyi State University, Abakaliki - Nigeria \\ Prof. S. N. Agwu, FCON, MNAE \\ Department of Arts and Social Science Education \\ Faculty of Education, \\ Ebonyi State University, Abakaliki - Nigeria
}

\begin{abstract}
The paper focused on biliteracy and multilingualism: implications of English language classroom interactions in Nigeria. The effectiveness of the use of English language depends on what learners are taught in the classroom. Teachers' proficiency in the use of English language determines the extent of learner's performance linguistically. Nigeria as a multilingual and biliteral nation cannot avoid learners of different language backgrounds in her various institutions of learning. For efficiency, the paper considers among other things; biliteracy, multilingualism, efficient strategies for English language classroom interaction, the use of response protocol in English language classroom interactions. These issues are raised in line with linguistic challenges that confront both the teachers and the students in the course of English language interactions with particular reference to language diversities in Nigeria. The scholars also drew attentions to various techniques teachers can employ in order to enhance and improve the learners understanding of the English language in Nigeria. Conclusion was drawn based on the issues and ideas raised in the paper.
\end{abstract}

Keywords: Biliteracy, Multilingualism, Classroom and Interactions

\section{Introduction}

Biliteracy as a concept stems from and belongs to the morphological family of bilingualism. This is the ability of an individual who is educated and literate to function effectively in more than one language. Biliteracy is the individual skills to communicate effectively in a formal setting.

In relation to that biliteracy means two tongues, that is to say that an individual may be described as having two tongues if he is described as a biliteracy person. Tongue here, has its traditional metaphorical meaning, it means language (Gyang, 2013). It is not only an individual that can be said to have two languages; there are societies, countries or nations in which more than one language is spoken. Thus, biliteralism or biliteracy is the existence of two languages in the repertoire of an individual or a speech community. A bilateral person is he who has the ability to function communicatively and competently in two languages.

\section{Biliteracy and Multilingualism}

Multilingualism in speech communication has to do with the use of many languages within a community or society of a group of people. Similarly, Nigeria is multilingual nation where English language is regarded as the lingua franca and the national language. It is the language of government, politics, economy, administration and the medium of instruction in the classroom. Among over four hundred languages are Hausa, Igbo, Yoruba Etik, TIV, Ibibo and many others which occupy the status of regional languages. In such a multilingual setting such as Nigeria, the unifying function of the English language becomes significant. There is every tendency that a child who grew up in this kind of environment has chances of becoming a bilingual if not a multilingual (Ghani, 2012). The common practice among Nigerians presently, is to ensure that their children/wards are trained to speak English language properly at home in order to be proficient in the use of English especially for academic purposes. Egele (2012), observes that as a result of the multiplicity of languages in Nigeria, English language has been adopted as the language of government, business, commerce, education and the mass media. 
Despite the clamour on debate about the desirability or otherwise the use of indigenous languages as medium of instruction in schools, the use of English language in classroom activities has come to stay. Ghani (2012), further asserts that textbooks in most subjects are written in English language, and there are more than $70 \%$ of verbal interactions between teachers and students in both primary and secondary school systems. Adegoke (2013), contends that in countries where English language has been adopted as the official language in place of their original indigenous language, there is indications that students low level of achievement in their academics may not be unconnected with their proficiency in English language.

The term multilingualism is a situation whereby individual group of people, society can function in more than one language. The category of multilingual is very broad; encompassing individuals who are sophisticated speakers, readers and writers of two or more languages, as well as those who use a limited knowledge of a second language $\left(\mathrm{L}_{2}\right)$ for purpose such as work or schooling, and who may be literate in only one. Because of the consequences of colonization, migration, nation-formation, traditions of exogamy, and modernization, some degree of multilingualism is typical of most people in the world (Claude, 2011).

Multilingualism is a feature not just of individuals, but also of societies. Societies, in which three or more than one languages have official status or recurrent functions, can be called multilingual. For instance, Nigeria is a good example of a multilingual society, but English language was selected by the colonial masters for administrative convenience. The nature of multilingualism in individual is quite different in different communities; there are those where multilingualism is the norm for all educated citizens and those where multilingualism is the norm for the minority language speakers but not those with the greatest political or economic power in the society (Ronald, 2010).

Multilingualism is often the product of second language $\left(\mathrm{L}_{2}\right)$ learning after the first language $\left(\mathrm{L}_{1}\right)$ has been acquired, either through non-tutored exposure or through instruction (Coleman, 2011). Individuals can become multilingual at any age, depending on when the need to lean the $\mathrm{L}_{2}$ emerges or when instruction becomes available. In some cases, though, multilingualism is a characteristic of a child's earliest language system. For instance children growing up in multilingual households, when both parents speak two or more language regularly or where each parent speaks a different language are typically multilingual from the very beginning of language acquisition. Moreso, children growing up with parents who speak a minority language (within the larger societal context) may also be natively multilingual, if visitors, neighbours, television, caretakers and other sources make the majority languages available (Simpson, 2013).

\section{Efficient Strategies for English Language Classroom Interactions}

It is imperative to assert that every parent all over the world strive for quality education of their children. For instance, there is need to define quality education to enable one differentiate it from less-preferred education. Similarly, there are many scholars; Hell, Crevola and Hopkins (2010) debates that there are some school variables which influence learners' proficiency and achievement in English Language, because it is dependent in English Language and also dependent of their background, classroom setting as well as societal factors. On the same view, it is also observed that factors like class size space, teachers' qualification, even the school size or environment are vital variables that play enormous roles in students learning English Language.

\section{- Quality Teaching}

It is opinated that quality teaching is tend to necessarily be student-centred. It aims to help most and for all students learning especially in the classroom. The focus here should not only be on pedagogical skills, but also on learning environment which students learning abilities in various degrees. Because of this, great emphasis has to be laid on "quality teaching" as advocated by many educators. In the same way, there is a need of elaborating the term "quality teaching". Globalization is another specific factor that influences every student learning style especially in the classroom (Nevin, 2009).

Most importantly, quality successful and effective learning actually depend on several factors such as availability and selection of instructional resource in English Language teaching, teacher quality and classroom interaction. According to Coleman (2003), one of the key features of quality teaching is student-centred classroom which aims at benefiting all learners.

\section{- Global Demands and Changes}

Learning environment along with teachers' pedagogical skills is important for English Language classroom interaction and quality education in Nigeria (Johnson, 2007). Similarly, the students have also become both geographically, socially and linguistically diversified. There is a great need for new teaching methods and pedagogies to meet global challenges especially in teaching and learning English Language in the classroom. Hence, there is need to say that there is need of change in the learners and teachers means of interactions. 
Most importantly, almost all the institutions of learning are striving to integrate curriculum with technology so that students are provided with quality education and effective learning of English Language (Pollock, 2013).

\section{- Assistance to Growth}

According to Alton-Lee (2014), the teachers should align their professional experiences with their teaching practices and pedagogies in order to benefit students in English Language classroom interaction. In line with the scholars view, nowadays one of the major roles of the teachers is to ensure that the content delivered has achieved the learning objectives, which can be considered as a key challenge. Despite the years of teaching experience, there is always a room for improvement and innovation for the teachers to adapt as pertain their requirements in language teaching development. According to Cather (2014), demands and needs change from time to time so the teachers should also undergo professional and personal development to benefit both the learners as well as themselves for effective classroom delivery.

\section{- Reflective Inquiry}

Pertinently, Depper (2012), suggests that the teachers would be able to change their teaching practices when they would reflect upon them and engage themselves in examining their own theories of teaching practices. But ironically, it is a fact that the teachers hardly get any time to reflect on their daily practices, leading to improvement. They believe that delivering the content which has been planned for a specific day and subject is the basic necessity, neglecting the fact that and being least bothered about knowing if the students learned or it was impossible for a student to grasp the basic conception in English language classroom interaction.

\section{- $\quad$ Effective Variables}

There are five variables which make teachers effective in the classroom interaction and delivery. These are clarity, task oriented, effectiveness, variability, enthusiasm and students opportunity to learn criterion material (Cather, 2014). These` are indeed a few components essential for a teacher to be known as effective, but there are more key elements which help the teachers personally and professionally and also the students.

\section{- Content (What) and Strategy (How)}

Most of the teachers think that they can improve their teaching practices through developing sound knowledge of content that needs to be taught and delivered (Hill and Crevola, 2012). This is a major setback in Nigerian schools. The teachers lose focus on their teaching strategies and they assume that the learners face difficulties because the content (what needs to be taught and delivered) is complicated or not of their interest instead of realizing the fact that the teaching strategy (how to teach and deliver) should be more effective to generate learner interest and better learning opportunities.

\section{- Unique Individuals with Different Learning Backgrounds}

All the world over, the educationists are well familiar with the fact that all the learners have different learning styles. The problem lies in catering for all of them with an effective teaching strategy; students learn in different ways in line with their capabilities. According to Felder (2009), some students learn by seeing, learning, reflecting, modeling, reasoning and drawing. In agreement with Felder's opinion, there also different teaching styles.

In furtherance to that view, some teachers give lectures, some discuss topics, some make their students work in groups, some use technological gadgets, some use textbooks. The main purpose behind these efforts is to help students grasp the content knowledge and align them with the real world scenario in learning English language as a second language in the classroom.

\section{- Teaching Strategies and Age Group}

It is important to recall that teaching strategies vary from one age group to another. None of the method is the best. It depends on the learning style of the students. Marzano (2012) observes that primary pupils take more interest in the activities performed in the class; in-class exercises work is the best for this age group. Visual and auditory aids improve learning performance of the learners in English language classroom interactions. The story is different in secondary and tertiary levels where lectures, projects, field work, group exercises and peer teaching are the most suitable strategies that improve learners' interest in English language learning.

\section{- The Use of Response Protocol in English Language Classroom Interactions}

Despite the need to use and develop their English language proficiency, English language learners (ELLs) are often quite during classroom interactions. The response protocol was developed to help teachers elicit and support the oral interactions of English language learners. 
According to Mohr (2012), in order to be proficient and productive students, English language learners (ELLs) need many opportunities to interact in social and academic situations. Effective teachers encourage their students' participation in classroom interactions, welcome their contributions and motivate them by such practices.

Many educators often allow their less proficient students to remain silent or to participate less than their English-fluent peers (Stipek, 2014).

Most importantly, teachers can elicit more information from the less proficient or reticent students if they consider various responses, options and then enlarge their response repertoires in order to encourage students' participation and help develop their language proficiencies. Johnston (2014), opines that there are several reasons why ELLs may struggle to respond appropriately to teachers' prompts and questions. Certainly, not all teachers' questions are clearly understood by students, and if such is the case teachers should rephrase or clarify queries in order to facilitate students' comprehension. Similarly, teachers may also not wait long enough for students to consider a question and formulate a response (Cazden, 2013). In addition, while first-language learning is largely motivated by a child's intrinsic desire to socialize; second-language learning often needs more extrinsic influence. Gibbons (2013), asserts that model of secondlanguage learning identified three motivational components that contribute to students' progress; which include; interest from the learners, proficient speakers who support and interact with the learners, and an environment that supports relationships between learners and proficient speakers. Sometimes students may not want to participate if the teacher expects them simply to recite low-level knowledge or if the teacher sets low expectations for the students.

\section{- Typical Classrooms}

From all indications, classroom interactions events vary. Research indicates that teacher talk dominates classroom communication. Edwards (2012), documents that teachers perform 76\% of classroom talk. Then Yuen (2013) observes that teacher talk consists of explanations, questions, commands, modeling and feedback. Thereupon, the preponderance of teacher talk and the teachers use of questions continue as factors in how much classroom talk time is shared, with students; both the quantity and quality of such interaction deserve scrutiny. Mercer (2012) observes that there are differences between direct and indirect instruction; the nature of large group discussion requires more guidance from the teacher than do small group interactions and English language learners may need different support in their communication efforts than do fluent English speakers.

Asking and answering questions are typical interactions and are expected in most Nigeria classrooms. In this manner, there exists what is referred to as the "Initiation-Response-Evaluation" sequence which is similar to "reaction questioning". The efforts usually stimulate the learners to response positively in learning English language. Another way of interacting with learners is feedback, here the teacher does more praise or evaluate the students response such as feedback can achieve a variety of goals, it can clarify, connect and elaborate the verbal interaction between teachers and students (Williams, 2001:23).

Similarly, Cazden (2013:106), "differentiated teachers display questions from exploratory queries. Display questions have specific and generally agreed-upon answers while exploratory talk is speaking without the answers fully intact". Display queries function to confirm the teacher's instruction while the latter is more confirming of the students as they exercise self-expression and refine their thinking. It is indicated that "if the potentialities of classroom interactions in which the students talk more and in more varied ways are significant for all students who are learners of the English language.

Another classroom interaction is the "instructional conversation". This interaction is characterized by an excellent discussion that is interesting, engaging, relevant to students, and discernible throughout and that has a high level of participation that build upon; challenges extends, and varies the roles of the participants-teachers and students. One major role of the teacher in instructional conservations according to Weber (2012), is what is called "conservational updates", connective comments that respect the students and effort linguistic scaffolds that faster more and better discussion of academic topics. In support of the view above, Scribner (2013:14) points out that "teachers who apply the concept of instructional conservations embrace the philosophy that talking and thinking go together, and assume that the students may have something to say beyond the student-teacher or peer is thinking or already knows. Clearly, English language learners may not have sufficient English to readily express ideas, so teachers must respond on ways that facilitate English language learners efforts to share their thinking and contribute ideas in the classroom communication.

\section{Responses that are correct}

If a student responds with a suitable answer to a teacher-generated question, the teacher may be gratified by the student's confirmation of the teaching-learning process. Most teachers praise students for correct responses. 
However, if the question-answer sequence attends to low-level thinking processes (e.g., recall, yes or no items, confirmational queries), teachers can make appropriate use of praise (Yuen, 2013)), but they should also encourage students to elaborate their responses. English language learning know more than they might readily speak of, so even when giving an appropriate response, they should be encouraged to tell more, to explain their answers, or to elaborate their responses (see Table 1 below).

Another element to add to appropriate responses is a confirmation that the student's use of English is effective. Even if uttered in nonstandard English, if the message is comprehensible and evidences, the student's understanding, commenting about the correctness and comprehensibility of the English should serve to encourage participation and elaboration on the part of the students. If a student provides even a partially correct response, the teacher can value the contribution, reinforce the correct portion, and then attempt to refine the response (see Table 2 below). Students have prior knowledge of the world that they make use of at school. However, sometimes their prior knowledge is limited and they need help to accommodate new learning into their schemata. Partially correct responses provide an excellent opportunity to students' thinking, to clarify their knowledge on a certain topic, and to lead to new learning (Clay, 2013).

\section{Table 1}

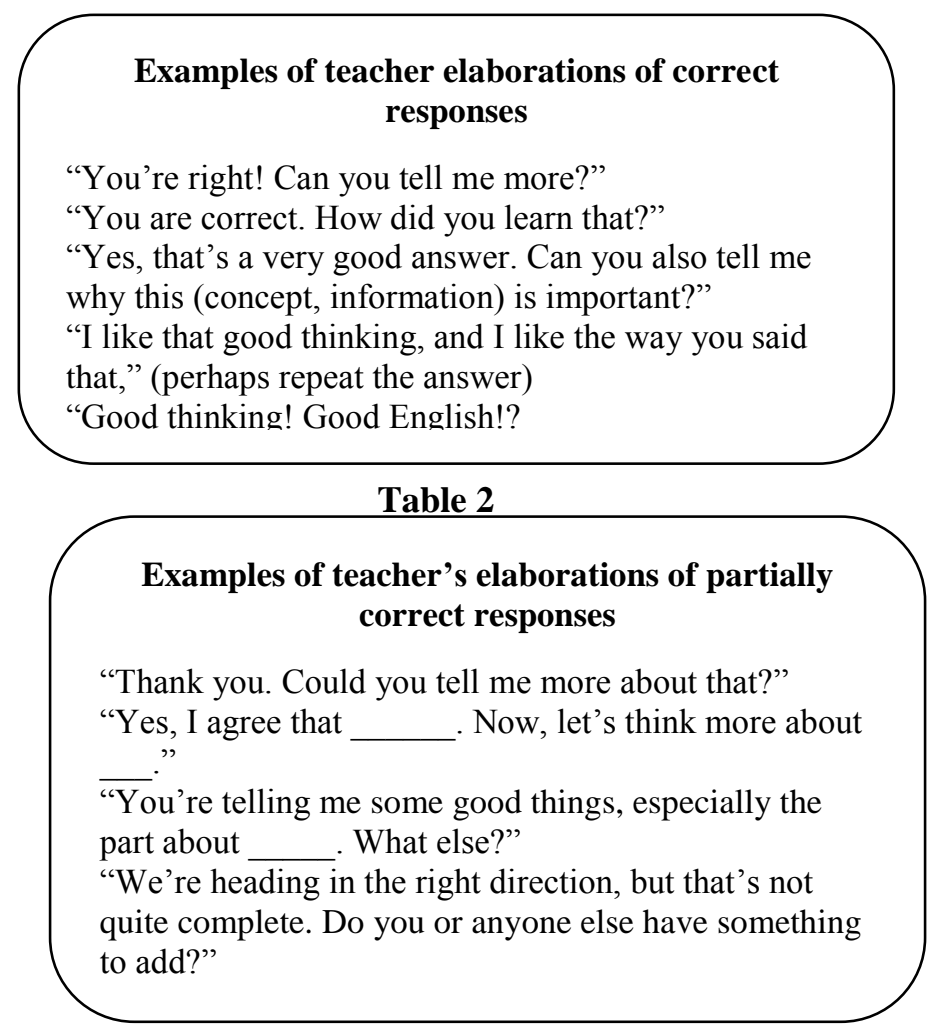

It can be very frustrating for monolingual English teachers to have students use their first languages, rather than English to respond in class. Some teachers perceive that students who do so are being inconsiderate, but rather teachers can choose to see this behaviour as encouraging (see Table 3 below). At least such a student seems to be interested and transacting with the lesson. In fact, studies show that students' other-language talk in classrooms is often largely on task (Kasten, 1997; Valdes, 1998). Even when students who share a common first language are whispering to one another, their language usually revolves around explaining what the teacher is talking about or clarifying the procedures that the students are expected to complete. Generally, teachers should not feel threatened when other languages are spoken in their classrooms. In fact, some young learners sometimes don't know which of their words and structures are or are not English. This example evidences the language transference confusion that can occurs so teachers should not be surprised when especially young students mix and match their languages. 
Table 3

\section{Examples of teacher elaborations of responses in a language other than English}

"All right. That sounds interesting to me. How can we say that in English?" (Wait and model conventional English.)

"Do you know any words in English to say that?'

"Call on someone (one of your friends) to help tell us what you said in English."

"Can you help us translate that into English?" (Repeat the question; call on more than one student, and then model an appropriate response in English.)

Given the preponderance of teacher talk as mentioned previously, students' questions might be rare or unexpected. But students' queries are important diagnostic opportunities for teachers and should be appreciated and responded to carefully (see Table 4). In a particular high-performing first-grade classroom known to the authors, the teacher had a jar of 100 marbles at the front of the room. She used the marbles to encourage students questions. The challenge was that for each student's question that was asked "to help all learn more," the teacher would move a marble from one glass jar to another glass jar. When the 100 marbles were all transferred to the second jar, the class could plan a special reward. The students' goal was often to earn more recess or a popcorn party, but the teacher's goal was to encourage good questions that benefited everyone in the learning process. The students learned that good students have good questions and that not knowing something was part of the process, as long as one asked questions to find out more. These students were motivated to ask questions that the teacher would acknowledge with a marble, and the questioning process afforded opportunities for more learning in a shared community.

Table 4

\section{Examples of teacher responses to student} questions

"Thank you for asking. Understanding is important.

Good learners ask lots of questions."

"Thank you for asking a question. Questions can help us all be better learners."

"Wow! That is a great (or important) question. Do you know anything that will help you answer that questions?"

"I am glad you asked that question. How can the rest of us answer your question?"

"Let me first answer your question, and then I will ask my question again."

"Do you want to call on another student to answer your question? Do you want one of your classmates to help you?"

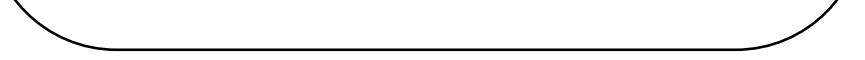

Table 5

\section{Examples of teacher elaborations of incorrect or confusing responses}

"Help me understand what you mean. Tell me again."

"Tell me more so I know what you're thinking."

"I want to know what you are thinking. Can you tell me more?"

"You said . But, I thought that . Please, help me understand." "Do you think__ or ___ ? " (Give a right answer as one of the options.) 
Again, when students respond incorrectly or insufficiently to teacher questions, the teacher can feel disappointed because the teaching-learning process does not seem to be proceeding smoothly and efficiently. However, teachers must avoid the temptation to blame the students for not listening or processing the question well. Instead, the teacher should use incorrect responses as a means of ongoing assessment to determine students' needs and misunderstandings (Hudelson, 1984). If teachers check students understanding during instruction, rather than wait until the end of the lesson, the teacher has the opportunity to reteach or clarify misunderstandings (see Table 5). One differentiation the teacher can make regarding incorrect responses is whether the source of the miscommunication is content or language based. Some students lack the linguistic ability in English to express themselves clearly, but this does not preclude their comprehension of the material. With support from the teacher, ELLs can refine their linguistic competence so that they can communicate their knowledge of content.

\section{Implications of Bilateracy and Multilingualism}

It is necessary to note that there are lots of implications of biliteracy and multilingualism in Nigeria. Historically, early biliteracy and multilingualism were seen as dangerous, leading to confusion and exacerbating language disorders and multilingualism may well bring cognitive advantages, particularly in demand such as helping children/ learners understand the arbitrary nature of language systems and literacy systems.

Obviously, the major positive implications of bilateracy and multilingualism are learning more than two languages, and thus being able to communicate with larger among individuals as well as having access to many cultural bodies of literature and many worldviews. For children in language minority communities, maintaining their ancestral language, preserves ties to their grandparents and keeps the option of expensive that build ethnic identification and pride as well as cultural continuity.

Speaking other languages also has economic advantages, as multilingual are in demand in the new global economy. In situation like this, there is every tendency that learners may face the challenges of which language should gain priority over the other. This is the major problem that contracts learners of English language and their achievement in the classroom in Nigeria.

\section{Conclusion}

Biliteracy and multilingualism are congruity variables that bother on individual abilities to function effectively in various languages other than the user's first language. The guidelines discussed in the paper can help the teachers to become more exploratory in their classroom interactions with students of varying language skills, intellectual levels and dissections. Nigeria as multilingual nation needs a holistic approach to address the issue of biliteracy and multilingualism in English language classroom interactions as a means of improving both students and teachers performance in social contexts.

\section{References}

Adegoke, B.A. (2013). Impact of indigenous language on students learning outcomes in secondary school. Journal of Languages, 52, 162-168.

Alton-Lee, M. (2014). Multiple voices: An introduction to bilingualism. Malden, MA: Blackwell Publishing.

Brophy, J. (1981). Teacher praise: A functional analysis. Review of Educational Research, 51, 5-32.

Cather, W.L. (2014). Linguistic imperialism. Oxford: Oxford University Press.

Cazden, C. (2013). Language, power and pedagogy: Bilingual children in the crossfire. London: Longman.

Claude, A. (2011). Language and education: literacy and culture. New York: Teachers College Press.

Clay, M. M. (1993). Reading recovery: A guidebook for teachers in training. Portsmouth, NH: Heinemann.

Coleman, A. (2003). Conservational interaction in secondary language. London: Macmillan.

Coleman, A. (2011). Effects of lingualism and biliteracy on children language development. Development Psychology, 30(2), 399-407.

Deppeler, F. (2012). Languages in contact: Findings and Problems. Netherland: Mouton \& Co.

Edwards, D. (2012). Common knowledge: The development of understanding in the classroom. New York: Methuen.

Egele, A.F. (2012). Ethnologue: Languages of the world. Dallas: Lex International.

Felder, V.M. (2009). Social organization in the classroom. MA: Harvard University Press.

Ghani, A.G. (2012). The sociolinguistic drawbacks in the English learning environment in a multilingual society. Review of Educational Research, 29(1), 58-65.

Gibbon, P. (2013). Scaffolding language teaching second language learners in the mainstream classroom. Portsmouth, NH: Heinemann.

Gyang, C. (2013). The bilingual advantage. New York: Times.

68 
Hill, I. and Crevola, E. (2012). Te natural approach: Language acquisition in the classroom. New York: Pergamon.

Hopkins, D. (2010). The impact of bilingual preschool education on language learning. TESOL Quarterly, 35(27), 1015.

Hudelson, S. (1984). kan yu ret an rayt en ingles: children become literate in English as a second language. TESOl quarterly, 18, 221-238.

Johnson, F.T. (2007). Multilingual: life and reality. England: Oxford University Press.

Johnson, P.H. (2014). Appropriate uses of $L_{1}$ and $L_{2}$. England: Arnold.

Kasten, W.C. (1997). Learning is noisy: The myth of silence in the reading-writing classroom. In J.R. Paratore \& R.L. McCormack (Eds), Peer talk in the classroom: Learning from research (pp.88-101), Newark, DE: International Reading Association.

Marzano, R.J. (2012). Teacher and classroom contact effects on students achievement. Journal of Personnel Evaluation, 10(7), 68-74.

Mercer, N. (2012). Teaching English learners strategies and methods. Boston: Allyn and Bacon.

Mohr, K.J. (2012). Extending English language learners classroom interactions using the response protocol. The Reading Teacher, 55(3), 445-448.

Nevin, A. (2009). Classroom interactions, comprehension and acquisition of $\mathrm{L}_{2}$. JALY Journal, 20(3), 55-63.

Pollock, J.E. (2013). Classroom instruction that works. Foreign Language Annals, 44(3), 62-69.

Ronald, G. (2010). Young bilingual children and early literacy development. New York: Guilford Press.

Scriber, (2013). Reading strategies of bilingual students. Reading Research Quarter, 31(2), 36-42.

Simpson, J. (2013). Language and linguistics. Handbook of early literacy. New York: Macmillan.

Stipek, D. (2014). A summary analysis of effective teachers discourse during literacy lessons. Journal of Classroom Interactions, 30(1), 20-26.

Weber, L. (2012). Inequality in the classroom: Teacher student interactions. England: Arnold.

William, J.A. (2001). Classroom discourse: The language of teaching and learning. Portsmouth, NH: Heinemann.

Yuen, S.D. (2013). Constructing knowledge together: classroom as centres of inquiry and literacy. Portsmouth, NH: Heinemann. 